\title{
Effect of barefoot walking on foot arch structure in Tribal children
}

\author{
Shanmukha Varalakshmi Vangara', Patnaik VV Gopichand², Minu Bedi ${ }^{3}$ Nidhi Puri ${ }^{4}$ \\ ${ }^{1}$ Ph.D Scholar, ${ }^{2}$ Professor and Dean, ${ }^{3}$ Professor, ${ }^{4}$ Professor and Head, Department of Anatomy, Maharishi \\ Markandeshwar Institute of Medical Sciences and Research, Maharishi Markandeshwar University, Mullana, Ambala, \\ Haryana, India
}

Background: The anatomy of human foot owes its adaptation to bipedal locomotion. Support and propulsion are the two main activities of foot which are possible due to segmental nature of foot. Bony architecture contributes to the arches of foot. Continuous stress put on the foot during childhood is expected to have changes in developing bone morphology. Pes planus and pes cavus are the two major foot deformities involving medial longitudinal arch. Aims and Objectives: The purpose of this study was to investigate the prevalence of pes planus and pes cavus among tribal children of Andhra Pradesh state in India. Materials and Methods: A sample size of 360 healthy tribal children, between the age group of 3-15 years, was randomly selected from Andhra Pradesh State. Anthropometric variables such as standing height and weight, foot length and width were measured. Height was measured using measuring tape and weight using weighing scale. Foot length and foot width were measured using osteometric board. BMI was calculated using the formula $\mathrm{BMI}=($ weight $(\mathrm{kg}) * 10000) /(\text { height }(\mathrm{cm}))^{2}$. Static foot prints of both feet were taken on graph sheets in both weight bearing and non weight bearing conditions. Arch index proposed by Cavanagh and Rodgers was followed to measure Medial longitudinal arch (MLA). MLA was classified $A I \leq 0.21$ as pes cavus, $A I=0.21-0.26$ as normal foot and $A I \geq 0.26$ pes cavus Results: Incidence of pes cavus was found to be higher than pes planus. Overall prevalence of pes planus was $26.4 \%$ \& $25.6 \%$ while pes cavus was $58.9 \% \& 66.7 \%$ for right and left foot respectively. Pes planus at 3-4 year age group was $60 \%$ and $63.3 \%$ which decreased to $16.7 \%$ and $30 \%$ at $14-15$ year age group for right and left foot respectively. Pes cavus at $3-4$ year age group was $33.3 \%$ and $33.3 \%$ while at $14-15$ year age group was $76.7 \%$ and $66.7 \%$ for right and left foot respectively. Conclusion: Pes cavus was found to be high among 3-15 year children. Age and gender were associated with foot arch structure. External factors like ethnic variations, hilly areas, bare foot walking; climbing trees might have a great role in influencing foot arch structure. Alteration from normal foot structure may influence the gait and lead to different injury patterns.

Key words: Medial longitudinal arch, pes planus, pes cavus, arch index
http://nepjol.info/index.php/AJMS DOI: 10.3126/ajms.v7i5.15241 E-ISSN: 2091-0576 P-ISSN: 2467-9100

\section{INTRODUCTION}

Feet are subjected to many ground reaction forces during daily activities. In order to balance the body weight the foot should act as a stable pedal platform capable of spreading stresses. Foot acts as a lever to resist thrust during walking, running and jumping. In order to perform the above said functions, foot is a complex segmented structure comprised of 26 bones held together by ligaments, extrinsic tendons and intrinsic muscles. Shape of the bones and attached ligamentous supports help in maintenance of the arch. Foot being segmented helps in shock absorption, propulsion, weight transfer and adoptability in uneven terrain. There are two anteroposterior arches, medial \& lateral and one horizontally running transverse arch. Disturbances in the foot arch lead to stress on the foot and thus extending 
throughout the lower extremity. Factors such as age, sex, ${ }^{1}$ weight, ${ }^{2}$ foot wear, ${ }^{3}$ occupation ${ }^{4}$ (like long term standing, carrying heavy loads, dancing, sports, athletes, gymnastics etc.) may influence the foot structure. Variation in the height of medial longitudinal arch (MLA) leads to two main common foot deformities, pes palnus and pes cavus. Pes planus is a flat foot condition in which MLA diminishes. High MLA is called pes cavus.

During infant stage foot appears to be flat due to the presence of plantar pad of fat. As the child starts to walk the foot attains its normal arch due to fat dissolution. Arch development finishes almost in the first decade of life. ${ }^{5}$ Flat foot can be physiological or pathological. In physiological flatfoot, the arch re-curves from a shift of weight bearing (WB) to non weight bearing (NWB) condition. The condition is called flexible pes planus (FPP). If the arch remains flat even in NWB condition, then it is rigid pes planus (RPP). Height of MLA high above the normal range in both WB and NWB conditions was considered as rigid pes cavus (RPC). Arch height diminishing only in weight bearing condition is considered as flexible pes cavus (FPC). Flexible foot arch conditions are generally asymptomatic. They become symptomatic if they continue to persist even in adults.

India accounts second largest tribal population in the world. ${ }^{6}$ As per 2001 census the population of tribes is $8.2 \%$ in India. In Andhra Pradesh 6.6\% constitute tribal population of the state. Koya constitutes $11.4 \%$ of total Andhra Pradesh tribal population. ${ }^{7}$ Current study is ethnic based to understand the foot conditions of tribal children of East Godavari district, Andhra Pradesh. Children belonging to Koya, Gotte koya, Konda reddy and lambadi tribes from different villages of East godavari district were randomly selected. They belong to Gonds which constitute the second largest tribal community in South Asia mostly occupying Eastern ghats. In the foot hills of papi range coexisting with Koyas are the Konda reddy tribe. The later are vulnerable and considered as one of the primitive tribal groups living in thick forests and high mountains. They are of shy nature and are reconciled to hills and valleys. They are brought up in open natural space continuously subjected to vigorous lifestyle. These indigenous tribes have their own unique cultural heritage. Formerly they were hunter gatherers and mainly shifting cultivators. These days they are settled cultivators due to complete ban on hunting wild animals. They cultivate paddy, maize, millet, tobacco. Collection of roots, fruits, leaves, tubers, herbs etc. from the nearby forest constitutes one of the important livelihood activities. They also collect minor forest produce like beedi leaves, gum, tamarind \& honey and non timber forest produce to sell them for their livelihood. They eat millet gruel, jowar, boiled leaves of various plants, bamboo shoots and fruits collected from forests. Cattle were taken to nearby forest for grazing and no other provisions are made to feed the animals. Children up to their adolescence were trained by parents to work as per the division of labour. They are also habitual bare foot walkers and tree climbers. Both men and children climb trees of Bassia Latifolia to get intoxicating beverage called 'ippa sara'. The ethnicity and life style is expected to have impact on the developing children's feet. To the best of our knowledge no previous studies were conducted on foot arch structure in this study population. This study provides a baseline data for arch indices of 3-15 year age group tribal children.

\section{MATERIALS AND METHODS}

After obtaining institutional ethical clearance the study was conducted in 360 healthy tribal children with 180 girls and 180 boys of 3-15 years age group. Prior consent was also taken from parents/guardians and school authorities. The information regarding age was confirmed from the school documents. Where the documentation was not available age was confirmed by parents. Subjests were selected randomly from Anganwadi, Aashram Schools in villages of East godavari district, Andhra Pradesh. All subjects were tribal children. Subjects were divided into 12 groups, of greater than three years and less than fifteen years, with 15 girls and 15 boys per group. Children other than tribal, age less than 3 years and greater than fifteen years, with a history of neuromuscular disease, foot deformities, injury to lower limb and any surgery to lower limb were excluded from study.

Age was recorded in years. Standing height was measured in centimetres using measuring tape and weight was measured in kilograms using weighing scale. Standing height was measured with head held in Frankfurt's plane, feet touching the floor and buttocks touching to the wall. Pockets of children were emptied and were made to stand bare footed on weighing scale for weight measurements. Weighing scale was set manually to zero before every reading. BMI was calculated and subjects were classified as underweight, normal weight, over weight and obese. Foot length and width measurements were taken in centimetres using osteometric board for both feet. The subject was made to stand barefoot on the osteometric board. Foot length was measured from posterior most point of the heel to the anterior most point of the foot i.e. great toe or second toe whichever is longest. ${ }^{8}$ Foot width was also measured from medial most point of first metatarsal head to the lateral most point of fifth metatarsal head. ${ }^{9}$ Ink footprints were retrieved on graph sheets using customized stamp pad. WB foot prints were collected in subject standing with both feet placed on graph sheet. NWB foot prints were collected in subject in seating posture. Foot prints were outlined using sharp pointed lead pencil. Smeared foot prints were 
excluded. The truncated foot length was measured from the foot prints excluding the area of the phalanges. A line from posterior most point of the heel to the second toe called Foot Axis was drawn. A perpendicular line was then be drawn to exclude the phalanges from the anterior most part of the foot. The plantar area, except for the digital area, was divided into three equal parts along the longitudinal axis of the foot, and the $\mathrm{AI}$ is the ratio between the midthird area and the total area. Greater values correspond to flatter feet, and lower values to high arch feet. $\mathrm{AI} \leq 0.21$ is considered as high arch foot, AI 0.21 to 0.26 as normal foot and $\mathrm{AI} \geq 0.26$ as low arch foot. ${ }^{10}$ The data were put to SPSS software version 16 for statistical analysis.

\section{RESULTS}

Out of 180 male and 180 female subjects, the average height was $128.85 \pm 20.2 \mathrm{~cm}$ and $123.61 \pm 18.9 \mathrm{~cm}$ respectively. Mean weight of males was $27 \pm 10.9 \mathrm{~kg}$ and that of females was $22.5 \pm 9.1 \mathrm{~kg}$. Mean foot length was $19.9 \pm 2.6 \mathrm{~cm}$ (Table 1). Mean BMI of males was $15.3 \pm 2.2 \mathrm{~kg} / \mathrm{cm}^{2}$ and that of females was $14 \pm 2.07 \mathrm{~kg} / \mathrm{cm}^{2}$. Under weight was observed in $11.7 \%$ of male and $26.1 \%$ of female children. Under weight was seen mostly in children less than 5 years of age. The general parameters like height, weight and body mass increased with age. Independent $t$-test was performed to analyse the statistical gender differences for various parameters. Boys had significantly greater mean values than girls. Foot parameters such as foot length and width also increased along with age in both boys and girls. Pearson's correlation test was done to observe relationship of general parameters with arch indices. All anthropometric variables were observed to be negatively correlated with the arch indices. No significant correlation $(\mathrm{p}>0.05)$ was observed for BMI and AI values (Table 2). One way ANOVA showed a significant difference in AIWB $(\mathrm{p}=0.00)$ \& AINWB $(p=0.03)$ mean values for different age groups (Table 3).
Post hoc multiple comparison test (LSD) was done to see differences of mean between any two groups. According to post hoc no significant difference was observed in AIWBR values of $6:<7$ years age group with other age groups in males and 5: <6 year age group with other age groups in females. This suggests that adult pattern was achieved one year earlier in females than males.

Line graphs of AIWB and AINWB for both right and left foot were shown in Figure 1 and 2 respectively. Cross tabulation was shown for gender differences $(p=0.00)$ in prevalence of unilateral and bilateral pes planus conditions (Table 4).

Unilateral pes planus was found in 30\% \& $29.4 \%$ males and $22.8 \%$ \& $21.7 \%$ females for right and left foot respectively. Bilateral pes planus was found in $21.7 \%$ and $15 \%$ males and females respectively whereas pes cavus was found in $46.7 \%$ \& $57.2 \%$ males and females respectively. Unilateral pes cavus was seen in $58.3 \%$ and $59.4 \%$ males and $73.9 \%$ \& $59.4 \%$ females for right and left foot respectively.

Categorical variables were tested using Chi square test for their association with foot arch structure (NF, FPC RPC, FPP, RPP) (Table 5).

Count and percentage of different arch types for right and left foot for both genders were depicted (Table 6). To provide the baseline data graphs showing different foot arch structures according to age were shown in Figures 3-8.

\section{DISCUSSION}

Humans are bipedal. The average child starts to walk without support at 1.5 years of age. The characteristic early gait matures rapidly and is similar to that of adult

Table 1: Descriptive statistics of various study parameters of males and females. Also shown are the values obtained by independent t-test

\begin{tabular}{|c|c|c|c|c|c|c|c|c|}
\hline \multirow[t]{2}{*}{ Parameters } & \multicolumn{3}{|c|}{ Male (180) } & \multicolumn{3}{|c|}{ Female (180) } & \multicolumn{2}{|c|}{ Independent t-test } \\
\hline & Mean & SD & SEM & Mean & SD & SEM & $T$ & Sig. (2-tailed) \\
\hline Height (cm) & 128.85 & 20.20474 & 1.50597 & 123.61 & 18.90271 & 1.40892 & 2.541 & 0.011 \\
\hline Weight (kg) & 27.0203 & 10.99872 & 0.81980 & 22.5878 & 9.18204 & 0.68439 & 4.151 & 0.000 \\
\hline BMI $\left(\mathrm{kg} / \mathrm{cm}^{2}\right)$ & 15.4283 & 2.38994 & 0.17814 & 14.0462 & 2.07196 & 0.15443 & 5.862 & 0.000 \\
\hline FLR (cm) & 19.9817 & 2.69437 & 0.20083 & 19.2761 & 2.50740 & 0.18689 & 2.572 & 0.011 \\
\hline FLL (cm) & 19.9850 & 2.69509 & 0.20088 & 19.2817 & 2.50959 & 0.18705 & 2.562 & 0.011 \\
\hline FWR (cm) & 8.0622 & 0.95474 & 0.07116 & 7.6133 & 0.85466 & 0.06370 & 4.700 & 0.000 \\
\hline FWL (cm) & 8.0650 & 0.95288 & 0.07102 & 7.6211 & 0.85887 & 0.06402 & 4.642 & 0.000 \\
\hline AIWBR & 0.23902 & 0.045436 & 0.003387 & 0.22356 & 0.051047 & 0.003805 & 3.034 & 0.003 \\
\hline AIWBL & 0.23700 & 0.051287 & 0.003823 & 0.22129 & 0.053403 & 0.003980 & 2.846 & 0.005 \\
\hline AINWBR & 0.17913 & 0.061199 & 0.004561 & 0.17116 & 0.067122 & 0.005003 & 1.178 & 0.240 \\
\hline AINWBL & 0.16353 & 0.070151 & 0.005229 & 0.13632 & 0.072744 & 0.005422 & 3.612 & 0.000 \\
\hline
\end{tabular}


Table 2: Correlation of age, height, weight, foot length and foot width with arch index

\begin{tabular}{|c|c|c|c|c|c|c|c|c|}
\hline Al & Age & Height & Weight & BMI & FLR & FLL & FWR & FWL \\
\hline \multicolumn{9}{|l|}{ AIWBR } \\
\hline Pearson correlation & -0.211 & -0.207 & -0.123 & -0.041 & -0.200 & -0.199 & -0.162 & -0.168 \\
\hline Sig. (2-tailed) & 0.000 & 0.000 & 0.020 & 0.441 & 0.000 & 0.000 & 0.002 & 0.001 \\
\hline \multicolumn{9}{|l|}{ AIWBL } \\
\hline Pearson correlation & -0.240 & -0.233 & -0.149 & -0.062 & -0.225 & -0.225 & -0.190 & -0.193 \\
\hline Sig. (2-tailed) & 0.000 & 0.000 & 0.004 & 0.239 & 0.000 & 0.000 & 0.000 & 0.000 \\
\hline \multicolumn{9}{|l|}{ AINWBR } \\
\hline Pearson correlation & -0.279 & -0.297 & -0.219 & -0.102 & -0.285 & -0.285 & -0.271 & -0.274 \\
\hline Sig. (2-tailed) & 0.000 & 0.000 & 0.000 & 0.053 & 0.000 & 0.000 & 0.000 & 0.000 \\
\hline \multicolumn{9}{|l|}{ AINWBL } \\
\hline Pearson correlation & -0.214 & -0.200 & -0.105 & 0.008 & -0.179 & -0.179 & -0.152 & -0.156 \\
\hline Sig. (2-tailed) & 0.000 & 0.000 & 0.047 & 0.878 & 0.001 & 0.001 & 0.004 & 0.003 \\
\hline
\end{tabular}

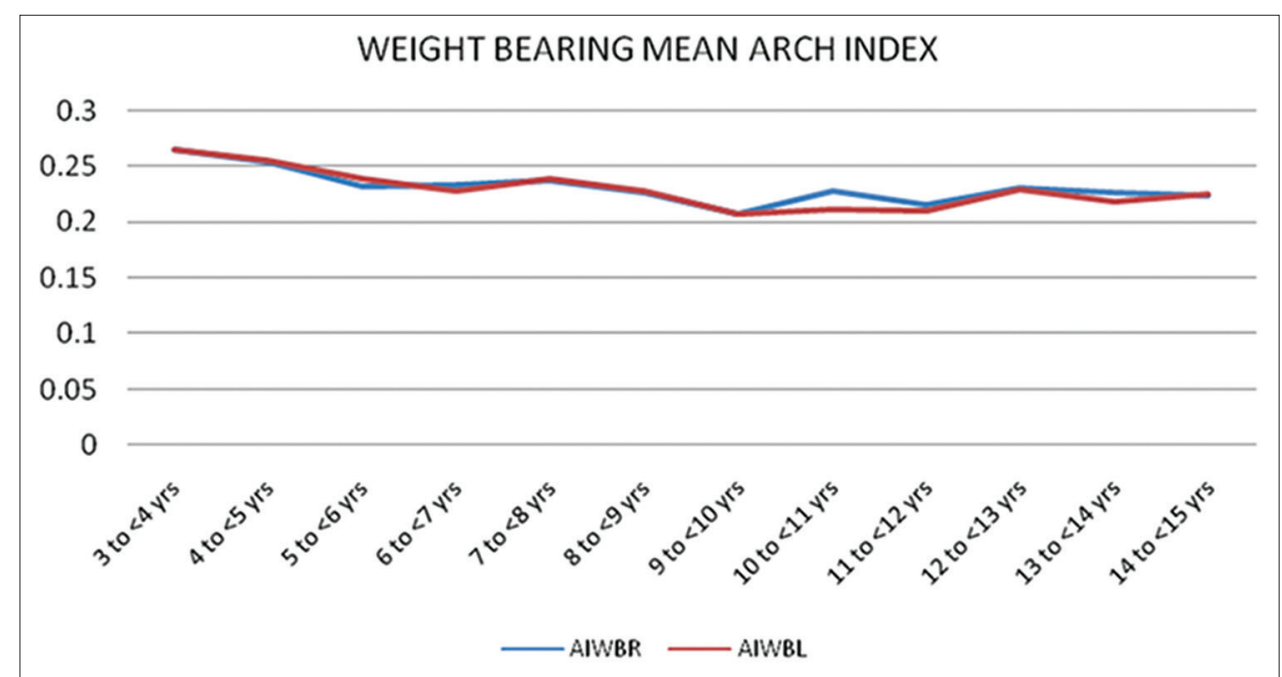

Figure 1: Line graph showing mean arch indices for different age groups in weight bearing condition $(\mathrm{N}=360)$

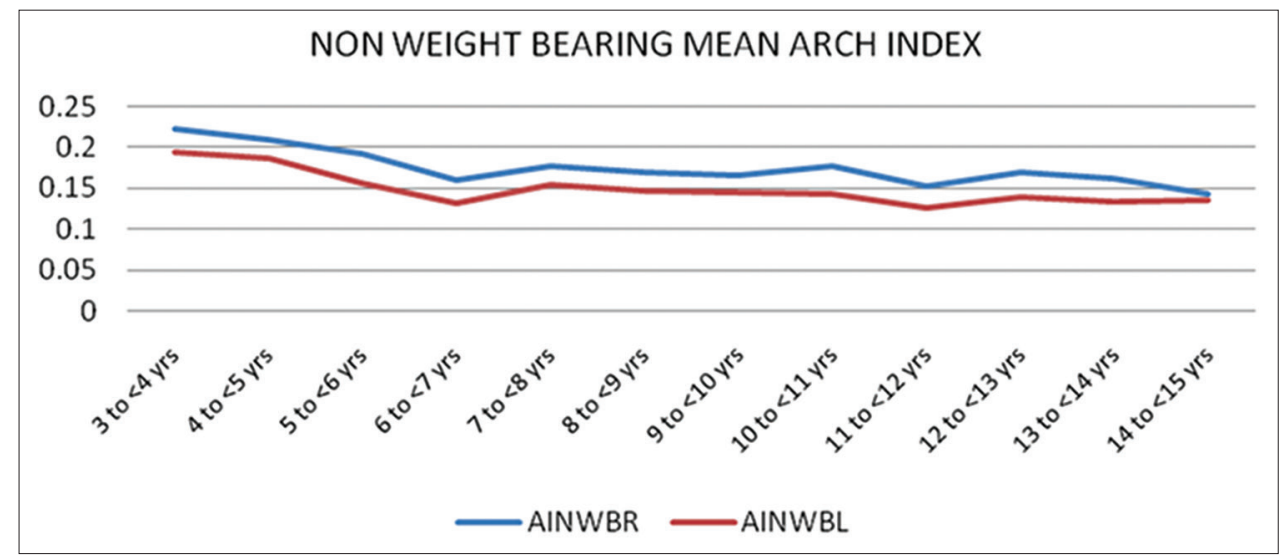

Figure 2: Line graph showing mean arch indices for different age groups in non weight bearing condition ( $\mathrm{N}=360)$

by 3 years. ${ }^{11}$ This is expected to have role on foot arch structure. Children's feet contain a high degree of cartilage making them more pliable and easier to be changed by external pressure. By 15-20 years of age the foot bones complete their ossification. ${ }^{12}$ As the child starts walking, plantar pad of fat dissolute and the foot arch structure is visualized..$^{13}$
Hence 3-15 years age group is crucial for foot structure development. To note the possible structural changes we considered 3-15 year age group children for our study.

Evaluation of foot arch by using foot prints is non invasive, reliable, cost effective and widely used clinically. ${ }^{14,15}$ Static foot prints can be easily collected without any special setup. 


\begin{tabular}{|c|c|c|c|c|c|c|}
\hline & \multicolumn{2}{|c|}{ Male } & \multicolumn{2}{|c|}{ Female } & \multicolumn{2}{|c|}{ Total } \\
\hline & F-value & Sig & F-value & Sig & F-value & Sig \\
\hline AIWBR & 2.411 & 0.08 & 2.288 & 0.012 & 3.239 & 0.000 \\
\hline AIWBL & 2.951 & 0.01 & 2.613 & 0.004 & 3.704 & 0.000 \\
\hline AINWBR & 2.168 & 0.018 & 2.297 & 0.012 & 4.050 & 0.000 \\
\hline AINWBL & 2.028 & 0.029 & 1.692 & 0.079 & 2.627 & 0.003 \\
\hline
\end{tabular}

This makes possible to approach even remote areas for data collection.

Urry et al. in 2001 investigated the relative accuracy of the measurements obtained from electronic footprints when compared with simultaneously acquired ink prints in a total of 96 subjects. They found that the ink foot prints are better than electronic foot prints because electronic prints underestimate the foot contact area. ${ }^{16}$ There were many studies that used foot prints for the assessment of flat foot. This study followed the method adapted by Cavanagh and Rodgers categorizing arch index as $\mathrm{AI} \leq 0.21$-- pes cavus, $\mathrm{AI} \geq 0.26$-- pes planus and $0.21-0.26$-- normal foot $(\mathrm{NF}) .{ }^{10}$

Gender differences were significant $(\mathrm{p}<0.05)$ for all parameters except for right side AI NWB. Descriptive statistics showed greater mean values in males than females (Table 1). AIWB mean values were in range for normal foot structure in both males and females. In case of AINWB the values were in pes cavus range. Independent $t$-test showed a significant difference in AI values between male and female children. Significant inverse but weak correlation $(p<0.05)$ was observed among AI values and various other parameters (Table 2).

ANOVA test showed significant differences $(\mathrm{p}<0.05)$ in AI values of different age groups (Table 3 ). As shown in Figures 1 and 2, the AI values were high in 3: $<4$ year age group children. Mean AIWB values reduced from 0.264 in 3: $<4$ years to 0.22 in case of $14-15$ year age group children for both right and left feet. Mean AINWB values were $0.22 \& 0.19$ in $3:<4$ years which reduced to $0.14 \&$ 0.13 in case of 14: $<15$ year age group children of right and left foot respectively. Our study was in well agreement with the study conducted in Karnataka, India, by Rao UB et al. ${ }^{17}$ which showed the prevalence of flatfoot decreased with age. They observed that children wearing closed shoes had higher incidence of flat foot than those who walk with slippers or bare footed. Subjects in our study were habitual barefoot walkers.

Both bilateral and unilateral pes palnus was higher in males than in females. Both bilateral and unilateral pes cavus was found to be higher in females than in males. Overall

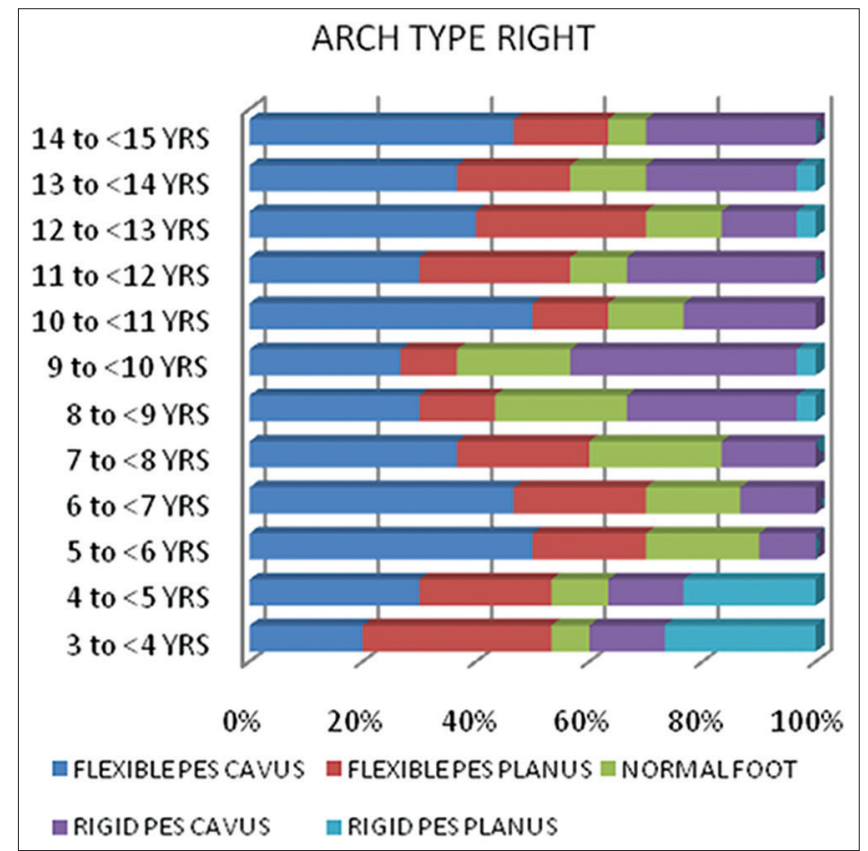

Figure 3: Graph demonstrating distribution of right foot arch types according to age groups for total study population $(\mathrm{N}=360)$

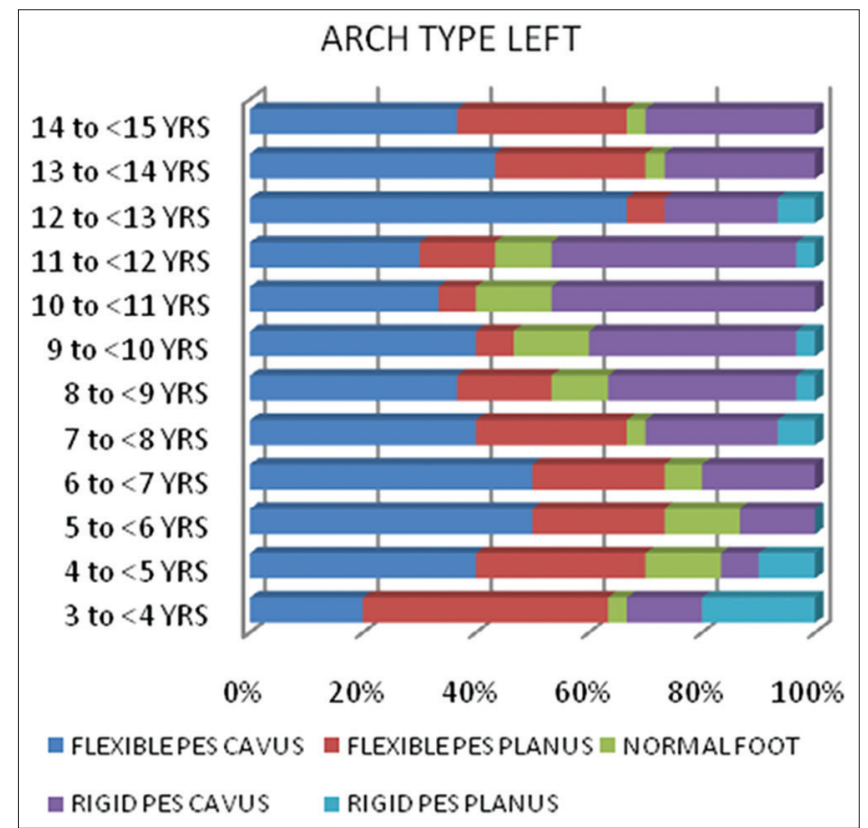

Figure 4: Graph demonstrating distribution of left foot arch types according to age groups for total study population $(\mathrm{N}=360)$

prevalence of flat foot was high in males than in females where as for pes cavus it was vice versa (Table 4). Several authors reported high incidence of pes planus in boys than in girls. ${ }^{5,14,18}$ Our study was in well accordance with them. Slower foot growth in boys may be a cause of high pes planus condition than girls.

Recoiling of arch structure should also be considered to rule out physiological foot deformity from a pathological 


\begin{tabular}{|c|c|c|c|c|c|c|c|}
\hline \multirow[t]{2}{*}{ Gender } & \multicolumn{3}{|c|}{ Left foot (\%) } & \multirow[t]{2}{*}{ Total (\%) } & \multirow[t]{2}{*}{ Value } & \multirow[t]{2}{*}{ Df } & \multirow[t]{2}{*}{ Asymp. Sig. (2-Sided) } \\
\hline & PP & PC & NF & & & & \\
\hline Right foot (\%) & & & & & 73.586 & 4 & 0.000 \\
\hline \multicolumn{8}{|l|}{ Male } \\
\hline PP & 21.7 & 6.1 & 2.2 & 30 & & & \\
\hline PC & 5.6 & 46.7 & 6.1 & 58.3 & & & \\
\hline NF & 2.2 & 6.7 & 2.8 & 11.7 & & & \\
\hline Total & 29.4 & 59.4 & 11.1 & 100 & & & \\
\hline Female (\%) & & & & & 86.762 & 4 & 0.000 \\
\hline PP & 15.0 & 6.7 & 1.1 & 22.8 & & & \\
\hline PC & 1.7 & 57.2 & 0.6 & 59.4 & & & \\
\hline NF & 5 & 10 & 2.8 & 17.8 & & & \\
\hline Total & 21.7 & 73.9 & 4.4 & 100 & & & \\
\hline
\end{tabular}

\begin{tabular}{|c|c|c|c|c|c|c|}
\hline & \multicolumn{3}{|c|}{ Right foot arch structure } & \multicolumn{3}{|c|}{ Left foot arch structure } \\
\hline & $\mathrm{X}^{2}$ Value & df & Asymp. Sig. (2-sided) & $\mathrm{X}^{2}$ Value & df & Asymp. Sig. (2-sided) \\
\hline Gender & 15.961 & 4 & 0.003 & 10.696 & 4 & 0.030 \\
\hline Age group & 32.211 & 8 & 0.000 & 26.895 & 8 & 0.001 \\
\hline
\end{tabular}

\begin{tabular}{|c|c|c|c|c|c|c|c|c|c|c|c|c|}
\hline \multirow[t]{3}{*}{ Arch type } & \multicolumn{6}{|c|}{ Right } & \multicolumn{6}{|c|}{ Left } \\
\hline & \multicolumn{2}{|c|}{ Male } & \multicolumn{2}{|c|}{ Female } & \multicolumn{2}{|c|}{ Total } & \multicolumn{2}{|c|}{ Male } & \multicolumn{2}{|c|}{ Female } & \multicolumn{2}{|c|}{ Total } \\
\hline & $n$ & $\%$ & $\mathbf{N}$ & $\%$ & $\mathbf{N}$ & $\%$ & $\mathbf{n}$ & $\%$ & $\mathbf{n}$ & $\%$ & $\mathbf{n}$ & $\%$ \\
\hline FPC & 78 & 43.3 & 55 & 30.6 & 133 & 36.9 & 68 & 37.8 & 78 & 43.3 & 146 & 40.6 \\
\hline FPP & 43 & 23.9 & 33 & 18.3 & 76 & 21.1 & 44 & 24.4 & 32 & 17.8 & 76 & 21.1 \\
\hline NF & 21 & 11.7 & 32 & 17.8 & 53 & 14.7 & 20 & 11.1 & 8 & 4.4 & 28 & 7.8 \\
\hline RPC & 27 & 15 & 52 & 28.9 & 79 & 21.9 & 39 & 21.7 & 55 & 30.6 & 94 & 26.1 \\
\hline RPP & 11 & 6.1 & 8 & 4.4 & 19 & 5.3 & 9 & 5 & 7 & 3.9 & 16 & 4.4 \\
\hline Total & 180 & 100 & 180 & 100 & 360 & 100.0 & 180 & 100 & 180 & 100 & 360 & 100.0 \\
\hline
\end{tabular}

one. For this purpose rigid and flexible foot arch conditions were categorized by combining the results of WB and NWB foot prints. Chi square test revealed the significant association between categorical variables and foot arch structure (Table 5). RPP was found only in 5.3\% out of $26.4 \%$ flatfoot in our study population (Table 6 ). Prevalence of RPP was $6.1 \%$ right and 5\% left where as $4.4 \%$ right and $3.9 \%$ left in male and female children respectively.

We found the prevalence of pes cavus to be higher in our study groups than the incidence of flat foot. These results were also in accordance with the study conducted by Sachitanandam V et al. ${ }^{19}$ in Indian population. They conducted study on 1846 skeletally matured persons of Karnataka. Even though they studied skeletally matured persons, the subjects belonged to rural areas. This study considered tribal children that were indigenous.
Figures 3 and 4 depict trend of different foot types for each group. Pes cavus condition tends to increase as the age advances in this study population.

RPC was seen in $28.9 \%$ and $30.6 \%$ females, $15 \%$ and $21.7 \%$ males for right and left foot respectively. FPC was observed to be $43.3 \%$ \& $30.6 \%$ of right feet and $37.8 \% \& 43.3 \%$ of left feet in males and females respectively.

Age was observed to be primary predictive factor for arch structure. As seen in Figures 5-8 normal foot arch development was noted earlier in females than in males. The incidence of pes cavus is more in higher age groups for both sexes. FPP was found in almost all age groups but RPP was observed in younger age groups and almost negligible tending towards higher age groups. Study conducted by George B et al. quoted the high incidence of pes cavus in south Indian barefoot tree climbers. ${ }^{20}$ 


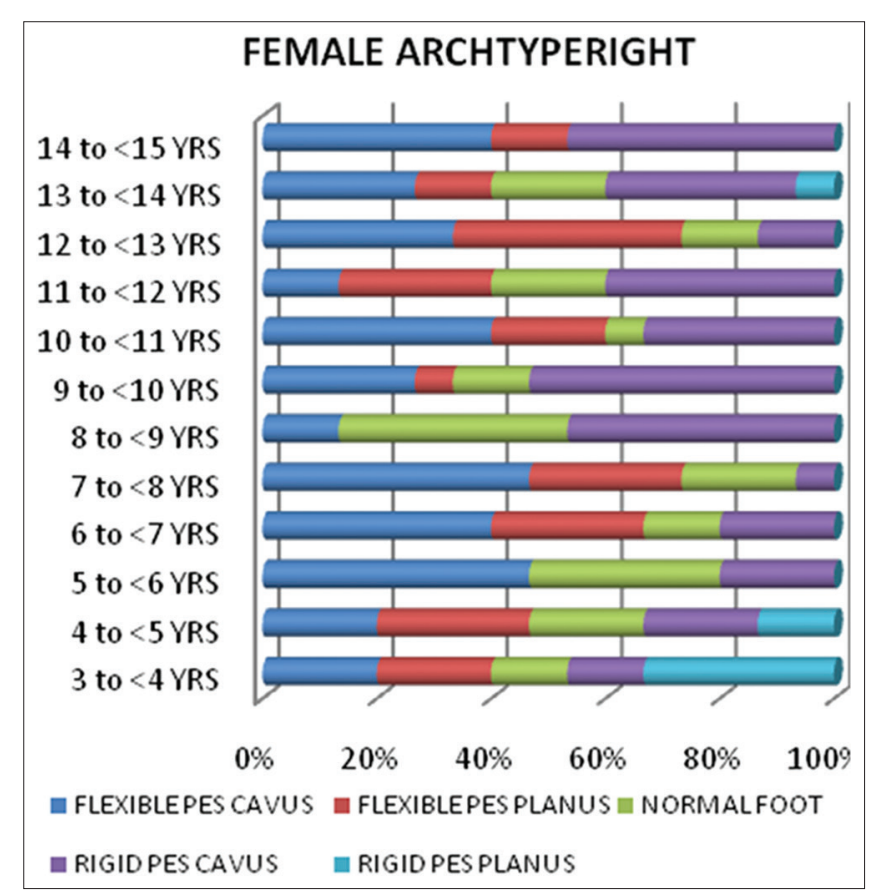

Figure 5: Graph demonstrating foot arch types of right foot according to age groups in female children

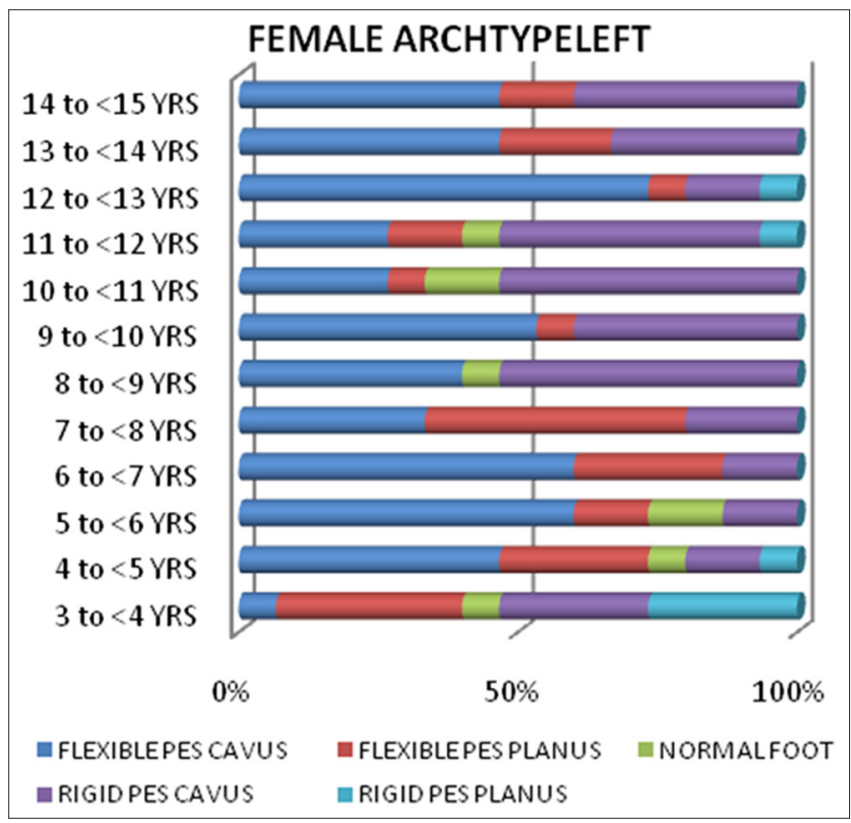

Figure 6: Graph demonstrating foot arch types of left foot according to age groups in female children

Previous reports have also suggested that there is a significant development of the MLA of the foot, particularly in the pre-school years. ${ }^{18,19}$ Although it is well established that the major morphological changes and adaptation of the foot occur during this period, this study demonstrates that ongoing development of foot structures also takes place during school ages. The low arched foot observed in young children may be a manifestation of constitutional laxity of the ligaments, which improves as

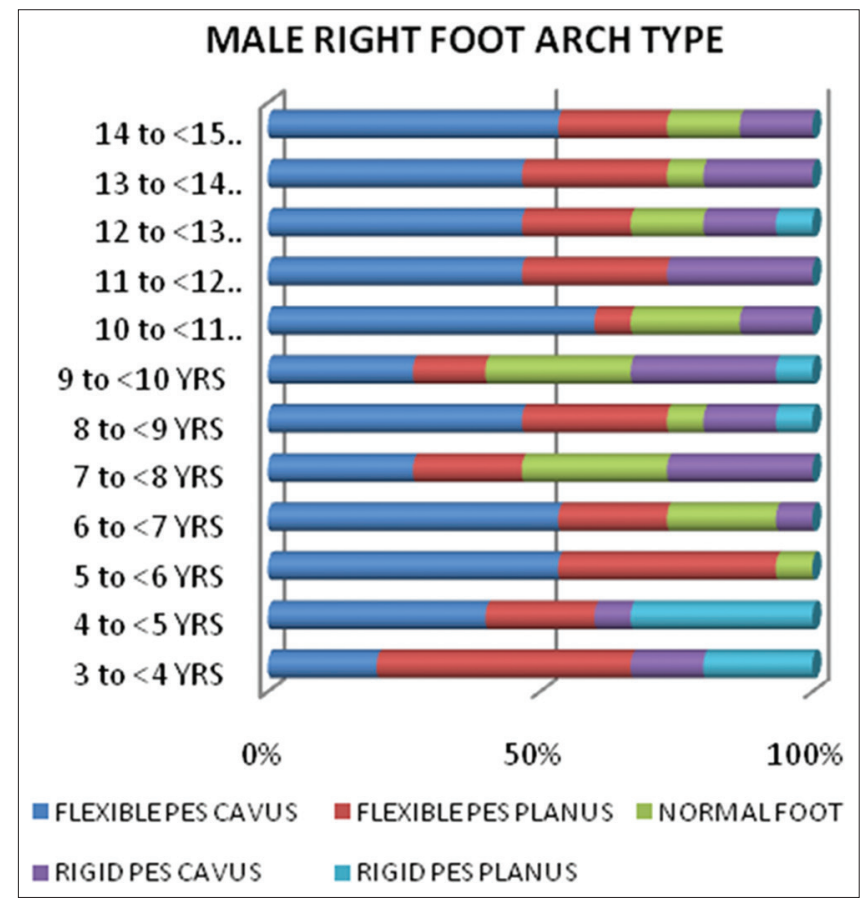

Figure 7: Graph demonstrating foot arch types of right foot according to age groups in male children

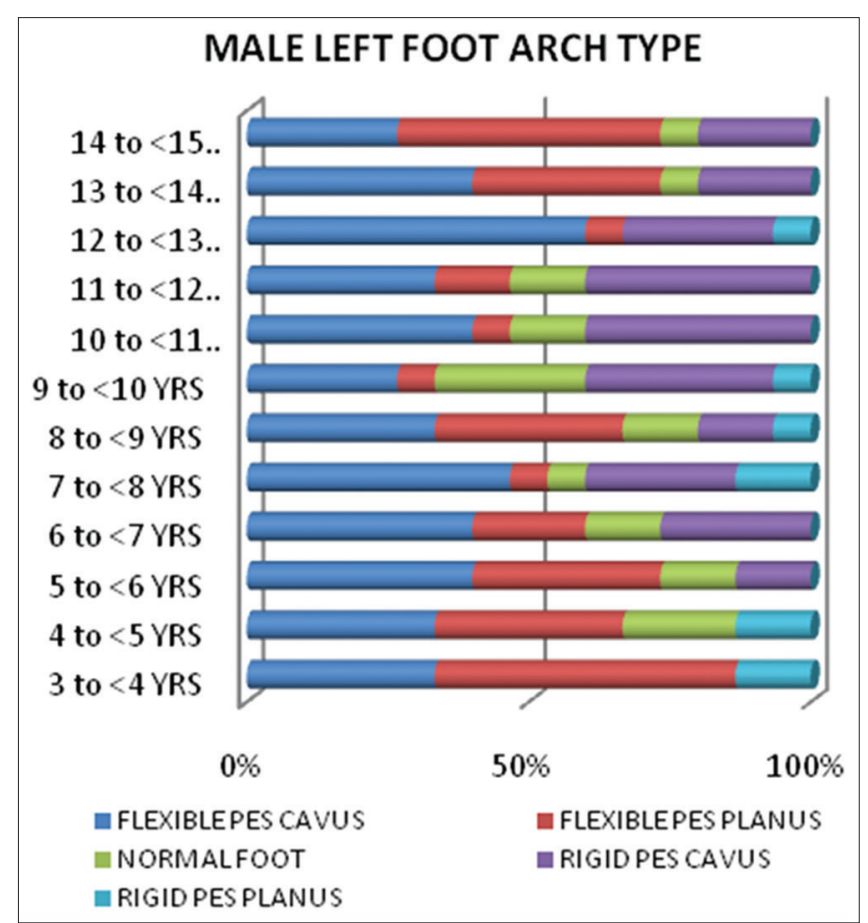

Figure 8: Graph demonstrating foot arch types of left foot according to age groups in male children

the foot matures ${ }^{1,19}$ and our study supports this over a wide range of ages.

Most of the studies conducted gave importance for determining flat foot. ${ }^{21,22}$ Even though pes cavus is less common in occurrence than pes planus, it is also a serious 
deformity that leads to abnormal distribution of weight on foot leading to instability. ${ }^{23}$ Literature is very scanty on occurrence of idiopathic pes cavus. ${ }^{24}$ During normal gait cycle enough pronation is required at calcaneus at the time of heel strike phase. In case of high arch foot inadequate pronation during heel strike is said to show stress on posterolateral structures of foot. This stress may aggravate further reaching to proximal kinematic chain and results in stress fractures. ${ }^{25}$ Thus shock related bone injuries are more common. Reason for the cause, prevention and treatment of pes cavus is not well known till today. FPC may become symptomatic as age advances and can lead to RPC condition. Few studies in habitually bare footed population proved that the strong contraction of intrinsic muscles occurs at the time of pronation reducing strain on soft tissues. ${ }^{26}$ This adaptive mechanism reduces the injuries in comparison to shod subjects. Study in Indian barefoot walkers conducted by Aout KD et al. found that wider feet in barefoot walkers help in reducing peak pressures and thus lowering the rate of injuries. They even recommended barefoot walking from early childhood. ${ }^{3}$ Difference in bony architecture could be of high significance to understand the underlying pathology which is out of preview of our study.

Prospective longitudinal studies are recommended for MLA and its effect on foot biomechanics.

\section{CONCLUSION}

Arch structure based on foot prints should always be evaluated in both WB \& NWB conditions. This favours proper differentiation of flexible and rigid deformities. This study provides a baseline data of foot arch structure for tribal children of 3-15 years age group. The bare foot walking on the hilly terrain is expected to be the cause for higher prevalence of pes cavus found even in early phases of life. The higher prevalence of high arch foot in children should be considered and taken care of. Correction of foot deformity, either pes planus or pes cavus, is imperative in children before attaining skeletal maturity. Barefoot walking was generally recommended for the better development of foot arch structure especially in the initial phases of life. But the high preponderance of pes cavus in children cannot be ignored. This ethnic variation is expected to be of great value for Podiatrists, Orthopaedicians, forensic experts and ergonomists.

\section{REFERENCES}

1. Umar MB and Tafida RU. Prevalence of flatfoot and anthropometric comparison between flat and normal feet in the Hausa ethnic group of Nigeria. J Am Podiatr Med Assoc
2013;103(5):369-373.

2. Evans AM. The paediatric flat foot and general anthropometry in 140 Australian school children aged 7-10 years. J Foot Ankle Res. 2011; 4:12.

3. Aout KD, Pataky TC, Clercq D and Aerts P. The effects of habitual footwear use: foot shape and function in native barefoot walkers. Footwear Sci 2009;1(2):81-94.

4. Desai SN, Grierson R and Manoli A. The cavus foot in athletes: fundamentals of examination and treatment. Oper Tech Sports Med 2010; 18:27-33.

5. Pfeiffer M, Kotz R, Ledl T, Hauser G and Sluga M. Prevalence of flat foot in pre-school age children. Pediatrics 2006; 118(2):634-639.

6. Chhetri DP. Tribal population and developmental policies in the Himalayan state of Sikkim: A critical analysis. Int J Soc Sci Humanit Invent 2013;2(5):8-18.

7. Subramanyachary P. Status of scheduled tribes in Andhra Pradesh. The Dawn Journal 2013; 2(1):336-343.

8. Singla R, Bedi $M$ and Biswas $M$. Sex estimation from foot anthropometry in Haryanavi jats and North Indian population. J Punjab Acad Forensic Med Toxicol 2012;12(1):13-16.

9. Patel SM, Doshi V, Ruparelia S, Zalawadia A, Parekh D, Rathod SP, et al. Anthropological study of the foot and it's relationship between different parameters and stature in an adult population of different areas of Gujarat. NJIRM 2011; 2(3):67-70.

10. Cavanagh PR and Rodgers MM. The arch index: A useful measure from footprints. J Biomech 1987; 20(5):547-551.

11. Standring $S$, editor, Ellis $H$, Healy JC, Johnson $D$, Williams $A$. Gray's Anatomy: The anatomical basis of clinical practice, $39^{\text {th }}$ ed. Spain: Churchill Livingstone 2008; pp.1532, 1534.

12. Palastanga $\mathrm{N}$ and Soames RW. Anatomy and human movement: Structure and function., $6^{\text {th }}$ ed. China:Churchill Livingstone 2012; pp 222.

13. Singrolay $R$ and Kushwah RS. Staheli's plantar arch index measured by simple footprint method is an effective diagnostic tool for flat foot as other radiological methods- A comparative study. IJSR 2015;4(9): 81-83.

14. Stavlas P, Grivas TB, Michas C, Vasiliadis E and Polyzois V. The evolution of foot morphology in children between 6 and 17 years of age: A cross-sectional study based on footprints in a Mediterranean population. J Foot Ankle Surg 2005; 44(6):424-428.

15. Forriol $\mathrm{F}$ and Pascual J. Footprint analysis between three and seventeen years of age. Foot Ankle 1990; 11(2):101-104.

16. Urry SR and Scott W. Comparison of footprint indexes calculated from ink and electronic footprints. J Am Podiatr Med Assoc 2001; 91(4):203-209.

17. Rao UB and Joseph $B$. The influence of footwear on the prevalence of flat foot: A survey of 2300 children. J Bone Joint Surg 1992; 74(4):525-527.

18. Mickle KJ, Steele JR and Munro BJ. Is the foot structure of preschool children moderated by gender? J Paediatr Orthop 2008; 28(5):593-596.

19. Sachithanandam $V$ and Joseph $B$. The influence of footwear on the prevalence of flat foot: A survey of 1846 skeletally mature persons. J Bone Joint Surg [Br] 1995; 77(B):254-257.

20. George BM, Kumar A and Rao MS. Foot deformations in coconut tree climbers of South India. NUJHS 2013;3(1):45-51.

21. Burns J, Landorf KB, Ryan MM, Crosbie $J$ and Ouvrier RA. Interventions for the prevention and treatment of pes cavus. Cochrane Database of Systematic Reviews 2007; (4). Art. No.: CD006154. DOI:10.1002/14651858.CD006154.pub2. 
22. Scherer PR and Choate CS. Current concepts in orthotic therapy for pes cavus. Podiatry Today 2008;21(10).

23. Idris $\mathrm{FH}$. The growth of foot arches and influencing factors. Paediatrica Indones 2005; 45(5-6):111-117.

24. Brewerton DA, Sandifer $\mathrm{PH}$ and Sweetnam DR. Idiopathic pes cavus: An investigation into its aetiology. Br Med J 1963; 2(5358):659-661.
25. Micheli LJ. Encyclopedia of sports medicine (e-book). USA:SAGE;2011 [cited 2016 Jun 20]. Available from: google ebooks.

26. Okutoyi PM. Foot arch characteristics and lower limb overuse injuries in habitually barefoot and shod Kenyan adolescents. Master of Medicine in Orthopaedic Surgery (Thesis). Moi University; 2013.

Authors Contribution:

SVV - Conducted the study, Data collection and analysis, Writing the manuscript; PVVG - Concept, Planning, Study design, Critical appraisal; MB - Concept , Planning; NP - Concept, Planning, Review of manuscript

Source of Support: Nil, Conflict of Interest: None declared. 